\title{
EVALUATION OF RETINAL DEGENERATION IN PARKINSON'S DISEASE
}

\author{
Arunava Kundu1, Krishan Kanta Roy², Nazneen Nazm³, Amitabha Das ${ }^{4}$, Biplab Biswas 5 , Sampurna Mukherjee ${ }^{6}$, Jitendra Kumar 7 , \\ K. Yella Ramudu ${ }^{8}$
}

${ }_{1}^{1}$ HOD, Department of Ophthalmology, ESI-PGIMSR, Joka.

${ }^{2}$ Senior Resident, Department of Ophthalmology, ESI-PGIMSR, Joka.

${ }^{3}$ Assistant Professor, Department of Ophthalmology, ESI-PGIMSR, Joka.

${ }^{4}$ Chief Medical Officer, Department of Ophthalmology, ESI-PGIMSR, Joka.

5Junior Resident, Department of Ophthalmology, ESI-PGIMSR, Joka.

6Junior Resident, Department of Ophthalmology, ESI-PGIMSR, Joka.

7 Junior Resident, Department of Ophthalmology, Command Hospital (EC), Kolkata.

8Junior Resident, Department of Ophthalmology, Command Hospital (EC), Kolkata.

\begin{abstract}
BACKGROUND
ABSTRACT

Parkinson's disease (PD) is a chronic, progressive neurodegenerative disorder that leads to the selective loss of dopaminergic neurons which leads to axonal loss of retinal nerve fibre layer. The purpose of this study is to evaluate the progressive changes in visual acuity and retinal thickness (RNFL and macular) over 3 years in PD patients.
\end{abstract}

\section{MATERIALS AND METHODS}

68 eyes of 38 idiopathic PD patients and same number of healthy controls whose sex and age were matched, underwent complete ophthalmic examination and structural analysis of the retina by SD-OCT with Cirrus HD OCT (CARL ZEISS). Both the groups were revaluated after 3 years to quantify changes in visual function parameters, retinal nerve fibre layer, and macular thickness. Progressive changes in visual acuity and retinal thickness (RNFL and macular) over 3 years were evaluated.

\section{RESULTS}

This current study shows patients with PD has significantly less BCVA both at baseline ( $0.62 \pm 0.2$ in PD vs. $0.52 \pm 0.22$ in controls $)$ and after 3 years $(0.63 \pm 0.25$ in PD vs. $0.54 \pm 0.24$ in controls) than control. Patients with PD have statistically significant RNFL thinning compared to that of controls both at baseline evaluation and after 3 years. On longitudinal followup compared to healthy controls, patients with PD had greater RNFL loss in temporal (7.55 in PD vs. 2.68 microns in controls) and superotemporal quadrants (5.47 in PD vs. 3.16 microns in controls).

\section{CONCLUSION}

This current study shows that in Parkinson's disease there is RFNL thinning and macular thinning which progress faster in diseased than in control. This is also reflected in best corrected visual acuity. So we believe that RNFL thickness and macular thickness can be used in the monitoring of patient compliance and treatment effectiveness.

\section{KEYWORDS}

Parkinson's Disease, Optical Coherence Tomography, Retinal Nerve Fibre Layer, Progression, Visual Dysfunction.

HOW TO CITE THIS ARTICLE: Kundu A, Roy KK, Nazm N, et al. Evaluation of retinal degeneration in Parkinson's disease. J. Evolution Med. Dent. Sci. 2017;6(95):7026-7029, DOI: 10.14260/jemds/2017/1524

\section{BACKGROUND}

Parkinson's disease (PD) is a chronic, progressive neurodegenerative disorder that leads to the selective loss of dopaminergic neurons, mainly in the basal ganglia of the brain. Though PD most commonly manifests movement disorder (i.e, bradykinesia, resting tremor, or rigidity), non-motor symptoms, such as dementia, depression, and autonomic dysfunction is also present in few cases. ${ }^{1}$

Vision is also altered in PD, especially the visual field corresponding to the fovea. ${ }^{2}$ These patients usually present with decreased low contrast visual acuity (LCVA), altered contrast sensitivity, and subtle colour deficiency. ${ }^{3}$

'Financial or Other Competing Interest': None.

Submission 02-11-2017, Peer Review 03-12-2017,

Acceptance 09-12-2017, Published 23-12-2017.

Corresponding Author:

Dr. Krishna Kanta Roy,

C/o. Dilip Roy, No. 30, Frazer Avenue,

Gurudashi North, Burdwan-713101.

E-mail: kkroy2020@gmail.com

DOI: $10.14260 /$ jemds $/ 2017 / 1524$
Dopaminergic neurons play an important role in mediating movements, motivation, mood and vision. Dopamine acts as a neurotransmitter in the retina. It is released by amacrine cells and it activates $D_{1} \& D_{2}$ receptors which is distributed throughout the retina.4,5,6 It is suggested that dysfunction of the intraretinal dopaminergic circuitry and altered retinal output to the brain is responsible for visual alteration. ${ }^{2}$

Recent studies have documented retinal thinning is less in healthy subjects as compared to that of many neurodegenerative diseases including PD, secondary to axonal loss. ${ }^{7,8,9}$ Retinal nerve fibre layer thinning is measured by spectral domain optical coherence tomography [SD OCT].

Like many neurodegenerative diseases, documentation of axonal loss (Retinal nerve fibre layer thinning measured by SD OCT) may provide an objective criterion in diagnosis and/or monitoring the progression of PD.

Though few researches on retinal changes in PD have been done, literature on progressive retinal changes in these patients is limited. To the best of our knowledge, this study is one of the first longitudinal studies, evaluating progressive 
changes in visual acuity and retinal thickness (RNFL and macular) over 3 years in PD patients.

\section{MATERIALS AND METHODS}

This prospective longitudinal study was conducted in a teaching hospital from January 2013 to March 2017. Patients with confirmed idiopathic PD were included in this study and was followed up. It included 68 eyes of 38 idiopathic PD patients and same number of healthy controls whose sex and age are matched. All the participants were evaluated at baseline and after 3 years.

All the procedures were performed in accordance to the tenets of the Declaration of Helsinki, and the study protocol was approved by the Institutional Ethics Committee. Informed consent was obtained from all the participants after explaining the nature of study. The diagnosis of PD was based on the United Kingdom Brain Bank Criteria. ${ }^{10}$

All patients underwent a complete ophthalmic examination as follows: Best corrected visual acuity, slit-lamp examination of the anterior segment, fundus examination with a plus 90-dioptre lens, intraocular pressure (IOP) measurement by applanation tonometry and gonioscopy.

Then the patients with significant refractive error (spherical equivalent $>5$ dioptres [D] or astigmatism $>3 \mathrm{D}$ ), media opacification, IOP $>21 \mathrm{mmHg}$, concomitant ocular diseases i.e. glaucoma, retinal pathology, optic neuritis antecedent were excluded from the study.

Patients having systemic conditions (e.g. diabetics, hypertension, neurologic pathology, and endocrine disorder) and/or taking systemic medications (such as chloroquine, antitubercular drugs, and anticonvulsants) that could affect the visual system were excluded from the study.

The subjects with no history and no evidence of ocular or neurologic disease of any nature, whose age and sex are matched, were included as controls.

Evaluation of visual function (best corrected visual acuity) and structural analysis of the retina by SD-OCT with Cirrus HD OCT (CARL ZEISS) was performed both at baseline and after 3 years.

Best corrected visual acuity (BCVA) was evaluated by lowcontrast ETDRS chart under monocular vision.

Retinal structural analysis was done in all the patients by SD-OCT with Cirrus HD OCT (CARL ZEISS), performed by single experienced operator, and the poor quality scans were rejected. Macular thickness analysis and RNFL thickness analysis were done.

\section{Statistical Analysis}

All variables were registered in Excel worksheet (Microsoft office 2007). All subjects were evaluated at the baseline and after 3 years. Statistical analysis was done using commercial predictive analytic software (SPSS 19 for Windows, Chicago, USA). The descriptive statistical methods which are used in the current study include: measures of central tendency by mean, and rate variability by standard deviation. Shapiro-Wilk tests, skewness value ("skewing") and kurtosis ("taper/flatness") were used to determine the normality of the sample distribution. The best corrected visual acuity (BCVA), RNFL and macular thickness were calculated and were compared between Parkinson's disease and the controls, by using
Student's t test at baseline and after 3 years. The change at baseline and after 3 years was noted. Significant statistical difference has been accepted if the $\mathrm{p}$ value is equal to or more than 0.05 .

\section{RESULTS}

We included 68 eyes of 38 patients with PD and same number of healthy controls. All of them were completely evaluated at baseline.

Total 10 patients were excluded from the study during followup period owing to severe physical impairment (n-03), death (n-02), impossibility to come to our OPD for evaluation (n-02), development of media opacity (n-02) and retinal disease (n-01).

5 controls were unable to come for a followup due to death (n-01), development of macular disease (n-02), media opacifications (n-01) and other personal reasons (n-02).

Finally, 50 eyes of 28 patients completed the 3 years followup satisfactorily, therefore, 28 controls were included in final statistical analysis.

The mean age was 68.9 years in patients with PD and 69.1 years in controls. The male to female ratio was $3: 2$ in both groups.

This current study shows patient with PD has significantly less BCVA both at baseline $(0.62 \pm 0.2$ in PD vs. $0.52 \pm 0.22$ in controls) and after 3 years ( $0.63 \pm 0.25$ in PD vs. $0.54 \pm 0.24$ in controls) than control. Greater loss of BCVA was observed in the PD group than in controls after 3 years of followup.

Retinal structural analysis is done by OCT both at baseline and followed by 3 years. On baseline evaluation, patients with PD have statistically significant RNFL thinning (96.40 \pm 10.45$)$, compared to that of controls ( $98.19 \pm 9.2)$. Maximum thickness difference was noted at superotemporal quadrant (125.89 \pm 18.04 in PD vs. $120.42 \pm 18.32 \mu$ in control.), followed by Inferotemporal $(101 \pm 29$ in PD vs. $151 \pm 23$ microns in controls.), temporal (72.43 \pm 12.3 vs. $65.88 \pm 13.53)$, Nasal (79.06 \pm 13.46 vs. $74.44 \pm 14.60)$, superonasal $(102.65 \pm 19.95$ vs. $100.64 \pm 19.65)$, inferonasal (113.89 \pm 18.56 vs. $109.64 \pm$ 20.03).

This is also reflected on 3 years followup. Then superotemporal $(101 \pm 29$ in PD vs. $151 \pm 23$ microns in controls) quadrant had maximum thickness difference followed by inferotemporal quadrant $(101 \pm 29$ in PD vs. 151 \pm 23 microns in controls), temporal quadrant (101 \pm 29 in PD vs. $151 \pm 23$ microns in controls) and nasal (74.44 \pm 14.60 in PD vs. $73.40 \pm 16.98$ microns in controls).

On longitudinal followup compared to healthy controls, patients with PD had greater RNFL loss in temporal (7.55 in PD vs. 2.68 microns in controls) and superotemporal quadrant (5.47 in PD vs. 3.16 microns in controls).

This study shows patients of PD has statistically significant macular thinning at baseline $(274.45 \pm 23.45$ in PD vs. 276.42 \pm 22.45 microns in controls) as well as after 3 years (272.34 \pm 41.34 in PD vs. $275.66 \pm 24.78$ microns in controls).

\begin{tabular}{|c|c|c|}
\hline & Parkinson's Disease & Control \\
\hline Age & 68.9 & 69.1 \\
\hline $\begin{array}{c}\text { Sex Ratio } \\
\text { (M: F) }\end{array}$ & $3: 2$ & $3: 2$ \\
\hline \multicolumn{3}{|c|}{ Table 1. Demographic Data } \\
\hline
\end{tabular}




\begin{tabular}{|c|c|c|c|c|c|c|c|c|c|}
\hline & \multicolumn{3}{|c|}{ Baseline } & \multicolumn{3}{|c|}{ After 3 Years } & \multicolumn{3}{|c|}{$\begin{array}{c}\text { Change in } 3 \text { years } \\
\text { 3rd Year Visit- Baseline Visit }\end{array}$} \\
\hline & \begin{tabular}{|c|}
$\begin{array}{c}\text { Parkinson's } \\
\text { Disease }\end{array}$ \\
\end{tabular} & Control & P Value & $\begin{array}{c}\text { Parkinson's } \\
\text { Disease }\end{array}$ & Control & P Value & \begin{tabular}{|c|}
$\begin{array}{c}\text { Parkinson's } \\
\text { Disease }\end{array}$ \\
\end{tabular} & Control & P Value \\
\hline $\begin{array}{c}\text { BCVA } \\
\text { (Low Contrast) }\end{array}$ & \begin{tabular}{l|}
0.62 \\
\pm 0.2 \\
\end{tabular} & $\begin{array}{c}0.52 \\
\pm 0.22\end{array}$ & 0.001 & \begin{tabular}{|c|}
0.65 \\
\pm 0.25
\end{tabular} & $\begin{array}{c}0.54 \\
\pm 0.24\end{array}$ & 0.001 & 0.03 & 0.02 & 0.012 \\
\hline RNFL average & $\begin{array}{r}96.40 \\
\pm 10.45 \\
\end{array}$ & $\begin{array}{c}98.19 \\
\pm 9.2 \\
\end{array}$ & 0.35 & $\begin{array}{l}92.87 \\
\pm 9.67 \\
\end{array}$ & $\begin{array}{r}95.73 \\
\pm 9.80 \\
\end{array}$ & 0.022 & 3.53 & 2.46 & 0.088 \\
\hline RNFL Temporal & $\begin{array}{r}72.43 \\
\pm 12.9 \\
\end{array}$ & $\begin{array}{r}71.66 \\
\pm 15.70 \\
\end{array}$ & 0.02 & $\begin{array}{r}65.88 \\
\pm 13.53 \\
\end{array}$ & $\begin{array}{c}68.98 \\
\pm 15.88 \\
\end{array}$ & 0.006 & 7.55 & 2.68 & $<0.001$ \\
\hline RNFL Nasal & $\begin{array}{c}79.06 \\
\pm 13.46 \\
\end{array}$ & $\begin{array}{c}78.14 \\
\pm 16.70 \\
\end{array}$ & 0.89 & $\begin{array}{c}74.44 \\
\pm 14.60 \\
\end{array}$ & $\begin{aligned} 73.40 \\
\pm 16.98 \\
\end{aligned}$ & 0.65 & 4.62 & 4.74 & 0.12 \\
\hline $\begin{array}{c}\text { RNFL } \\
\text { Superotemporal }\end{array}$ & $\begin{array}{r}125.89 \\
\pm 18.04 \\
\end{array}$ & $\begin{array}{l}132.02 \\
\pm 16.22 \\
\end{array}$ & 0.007 & $\begin{array}{l}120.42 \\
\pm 18.32 \\
\end{array}$ & $\begin{array}{l}128.86 \\
\pm 14.88 \\
\end{array}$ & 0.003 & 5.47 & 3.16 & $<0.001$ \\
\hline $\begin{array}{c}\text { RNFL } \\
\text { Inferotemporal }\end{array}$ & $\begin{array}{l}132.45 \\
\pm 17.85 \\
\end{array}$ & $\begin{array}{r}143.44 \\
\pm 16.40 \\
\end{array}$ & 0.002 & $\begin{array}{l}128.22 \\
\pm 16.88 \\
\end{array}$ & $\begin{array}{l}135.46 \\
\pm 18.44 \\
\end{array}$ & 0.001 & 4.23 & 7.98 & 0.45 \\
\hline RNFL Superonasal & $\begin{array}{l}102.65 \\
\pm 19.95 \\
\end{array}$ & $\begin{array}{l}105.70 \\
\pm 17.20 \\
\end{array}$ & 0.14 & $\begin{array}{l}100.64 \\
\pm 19.65 \\
\end{array}$ & $\begin{array}{l}103.84 \\
\pm 15.12 \\
\end{array}$ & 0.648 & 2.01 & 1.86 & 0.216 \\
\hline RNFL Inferonasal & $\begin{array}{l}113.89 \\
\pm 18.56 \\
\end{array}$ & $\begin{array}{r}115.10 \\
\pm 13.20 \\
\end{array}$ & 0.22 & $\begin{array}{c}109.64 \pm \\
20.03 \\
\end{array}$ & $\begin{array}{c}111.38 \pm \\
26.88 \\
\end{array}$ & 0.088 & 4.25 & 3.72 & 0.757 \\
\hline CMT (Average) & $\begin{array}{l}274.45 \\
\pm 23.45\end{array}$ & $\begin{array}{l}276.42 \\
\pm 22.45\end{array}$ & 0.87 & $\begin{array}{c}272.34 \pm \\
41.34\end{array}$ & $\begin{array}{c}275.66 \pm \\
24.78\end{array}$ & 0.62 & 2.11 & 0.76 & $<0.001$ \\
\hline
\end{tabular}

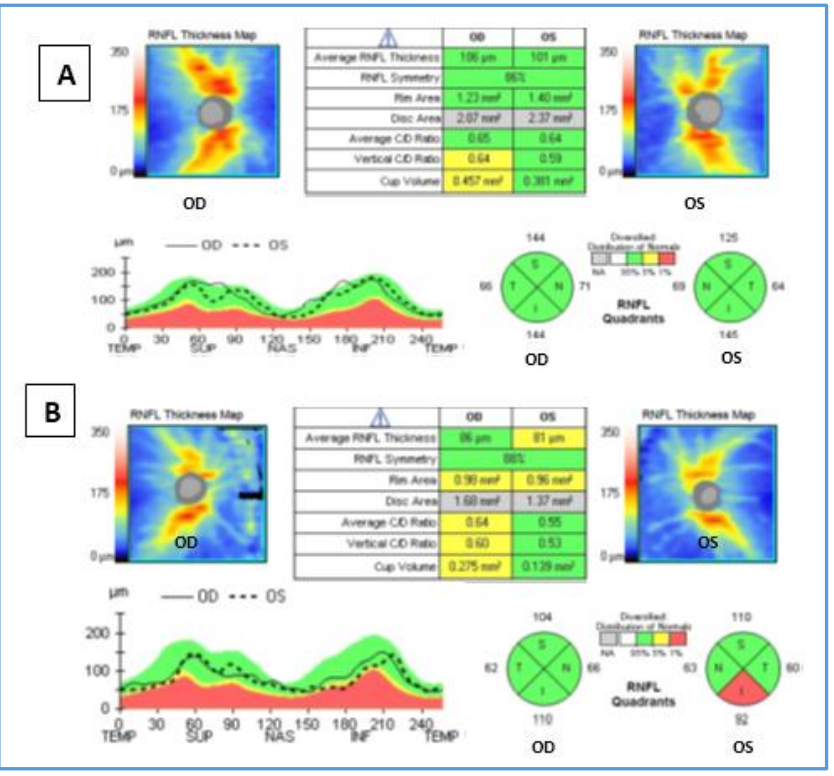

\section{DISCUSSION}

In Parkinson's disease, dopamine levels deplete. Previous studies showed that dopamine has very important role in light adaptation, ${ }^{10,11}$ spatial contrast sensitivity, colour discrimination.12,13,14 In this study, we have evaluated progressive changes in visual acuity and retinal thickness (RNFL and macular) over 3 years in patients of PD compared to that of controls.

In this study, at baseline evaluation, patients of PD had lower BCVA ( $0.62 \pm 0.2$ in PD vs. $0.52 \pm 0.22$ in controls) than controls which is also reflected after 3 years of followup $(0.65$ \pm 0.25 in PD vs. $0.54 \pm 0.24$ in controls). In the period of 3 years of followup, rate of visual acuity worsening is more in patients of PD than that in controls.

This study shows that patients of PD have lower BCVA both at baseline and after 3 years compared to that of controls.

Previously a study by Nowacka et $\mathrm{al}^{15}$ reported visual dysfunction and structural abnormality of retina in patients of
PD. They reported that this abnormality was secondary to dopamine depletion in the retina.

In this study, patients with PD have more axonal loss (RNFL thinning) compared to that of controls. In 2004, Inzelberg et al 16 first reported the inferotemporal peripapillary RNFL thinning in patients of PD and pointed out that structural changes of inner retina can be used as a monitoring tool for PD progression. Since then, several studies ${ }^{16-18}$ have demonstrated different results. Altintas et al, Lee et al $^{19}$ reported statistically significant RNFL thinning in cases of PD compared to that of controls. Whereas Bittersohl et al and Chorostecki et al ${ }^{20}$ didn't find any significant RNFL thinning in patients of PD compared to that of controls. But the current study shows significant RNFL thinning in patients of PD. This discrepancy among different studies was probably due to variation in sample size, study population and use of different OCT devices [Stratus OCT (Carl Zeiss Meditec, Inc., Dublin, CA, USA) versus Heidelberg OCT].

In this current study, we observed more progressive thinning of RNFL in patients of PD over 3 years follow up period than in controls. This finding corroborated with Lee et al, they found the association of RNFL thickness with duration and severity of the Parkinson's disease in their study. They also proposed that retina could be used as a biomarker for disease progression. ${ }^{19}$

The current study shows statistically significant lower macular thickness in patients of PD than in controls, both at baseline and after 3 years. Satue et $\mathrm{al}^{21}$ didn't find any statistically significant difference in between patients of PD and controls, both at baseline and after 3 years followup. Prior research done by Garcia Martin et al22 on other neurodegenerative disease like multiple sclerosis demonstrated progressive macular thinning. Segmental analysis of the retinal layers by Narayanan et al in the neurodegenerative disease suggests progressive loss of macular ganglion cell in multiple sclerosis. ${ }^{23}$

In this current study, we have several limitations, some of our participants might have subclinical glaucoma or normal tension glaucoma, though all the participants (PD and 
Controls) underwent IOP measurement and fundus evaluation by $90 \mathrm{D}$ lens. Since all the subjects didn't undergo automated perimetry, certain glaucomatous changes were not appreciated.

In this current study, we did not consider the treatment and pharmacological therapy which may have an impact on retinal axonal loss. By post-mortem analysis Harnois et al reported lower concentration of retinal dopamine in patients of PD, who are not treated with L-3, 4-dihydroxyphenylalanine (L-DOPA) than control. ${ }^{24}$

\section{CONCLUSION}

This current study shows that in Parkinson's disease there is RFNL thinning and macular thinning which progress faster in diseased than in control. This is also reflected in best corrected visual acuity. So we believe that RNFL thickness and macular thickness can be used in the early diagnosis of Parkinson's disease.

\section{REFERENCES}

[1] Park A, Stacy M. Non-motor symptoms in Parkinson's disease. J Neurol 2009;256 (Suppl 3):293-8.

[2] Bodis-Wollner I. Retinopathy in Parkinson disease. J Neural Transm (Vienna) 2009;116(11):1493-501.

[3] Polo V, Satue M, Rodrigo MJ, et al. Visual dysfunction and its correlation with retinal changes in patients with Parkinson's disease: an observational crosssectional study. BMJ Open 2016;6(5):e009658.

[4] Aaker GD, Myung JS, Ehrlich JR, et al. Detection of retinal changes in Parkinson's disease with spectraldomain optical coherence tomography. Clin Ophthalmol 2010;4:1427-32.

[5] Altintas O, Işeri P, Ozkan B, et al. Correlation between retinal morphological and functional findings and clinical severity in Parkinson's disease. Doc Ophthalmol 2008;116(2):137-46.

[6] Archibald NK, Clarke MP, Mosimann UP, et al. The retina in Parkinson's disease. Brain 2009;132(Pt 5):1128-45.

[7] Hajee ME, March WF, Lazzaro DR, et al. Inner retinal layer thinning in Parkinson's disease. Arch Ophthalmol 2009;127(6):737-41.

[8] Cubo E, Tedejo RP, Rodriguez-Mendez V, et al. Retina thickness in Parkinson's disease and essential tremor. Mov Disord 2010;25(14):2461-2.

[9] Garcia-Martin E, Satue M, Fuertes I, et al. Ability and reproducibility of Fourier domain optical coherence tomography to detect retinal nerve fiber layer atrophy in Parkinson's disease. Ophthalmology 2012;119(10):2161-7.

[10] Djamgoz MB, Hankins MW, Hirano J, et al. Neurobiology of retinal dopamine in relation to degenerative states of the tissue. Vision Res 1997;37(24):3509-29.
[11] Wink B, Harris J. A model of the Parkinsonian visual system: support for the dark adaptation hypothesis. Vision Res 2000;40(14):1937-46.

[12] Davidsdottir S, Cronin-Golomb A, Lee A. Visual and spatial symptoms in Parkinson's disease. Vision Res 2005;45(10):1285-96.

[13] Uc EY, Rizzo M, Anderson SW, et al. Visual dysfunction in Parkinson disease without dementia. Neurology 2005;65(12):1907-13.

[14] Price MJ, Feldman RG, Adelberg D, et al. Abnormalities in color vision and contrast sensitivity in Parkinson's disease. Neurology 1992;42(4):887-90.

[15] Nowacka B, Lubi'nski W, Honczarenko K, et al. Bioelectrical function and structural assessment of the retina in patients with early stages of Parkinson's disease (PD). Doc Ophthalmol 2015;131(2):95-104.

[16] Inzelberg R, Ramirez JA, Nisipeanu P, et al. Retinal nerve fiber layer thinning in Parkinson's disease. Vision Res 2004;44(24):2793-7.

[17] Satue M, Garcia-Martin E, Fuertes I, et al. Use of Fourier-domain OCT to detect retinal nerve fiber layer degeneration in Parkinson's disease patients. Eye (Lond) 2013;27(4):507-14.

[18] Bittersohl D, Stemplewitz B, Keser"u M, et al. Detection of retinal changes in idiopathic Parkinson's disease using high-resolution optical coherence tomography and Heidelberg retina tomography. Acta Ophthalmol 2015;93(7):e578-e84.

[19] Lee JY, Ahn J, Kim TW, et al. Optical coherence tomography in Parkinson's disease: Is the retina a biomarker? J Parkinson's Dis 2014;4(2):197-204.

[20] Chorostecki J, Seraji-Bozorgzad N, Shah A, et al. Characterization of retinal architecture in Parkinson's disease. J Neurol Sci 2015;355(1-2):44-8.

[21] Satue M, Rodrigo MJ, Obis J, et al. Evaluation of progressive visual dysfunction and retinal degeneration in patients with Parkinson's disease. Invest Ophthalmol Vis Sci 2017;58(2):1151-7.

[22] Garcia-Martin E, Pueyo V, Almarcegui C, et al. Risk factors for progressive axonal degeneration of the retinal nerve fibre layer in multiple sclerosis patients. Br J Ophthalmol 2011;95(11):1577-82.

[23] Narayanan D, Cheng H, Bonem KN, et al. Tracking changes over time in retinal nerve fiber layer and ganglion cell-inner plexiform layer thickness in multiple sclerosis. Mult Scler 2014;20(10):1331-41.

[24] Harnois C, Di Paolo T. Decreased dopamine in the retinas of patients with Parkinson's disease. Invest Ophthalmol Vis Sci 1990;31(11):2473-5. 